\title{
Stimulus-Dependent Translocation of $\kappa$ Opioid Receptors to the Plasma Membrane
}

\author{
Samuel J. Shuster, ${ }^{1,2}$ Maureen Riedl, ${ }^{2}$ Xinren Li, ${ }^{2}$ Lucy Vulchanova, ${ }^{2}$ and Robert Elde ${ }^{1,2}$ \\ ${ }^{1}$ Graduate Program in Neuroscience and ${ }^{2}$ Department of Cell Biology and Neuroanatomy, University of Minnesota, \\ Minneapolis, Minnesota 55455
}

\begin{abstract}
We examined the cellular and subcellular distribution of the cloned $\kappa$ opioid receptor (KOR1) and its trafficking to the presynaptic plasma membrane in vasopressin magnocellular neurosecretory neurons. We used immunohistochemistry to show that KOR1 immunoreactivity (IR) colocalized with vasopressincontaining cell bodies, axons, and axon terminals within the posterior pituitary. Ultrastructural analysis revealed that a major fraction of KOR1-IR was associated with the membrane of peptide-containing large secretory vesicles. KOR1-IR was rarely associated with the plasma membrane in unstimulated nerve terminals within the posterior pituitary. A physiological
\end{abstract}

stimulus (salt-loading) that elicits vasopressin release also caused KOR1-IR to translocate from these vesicles to the plasma membrane. After stimulation, there was a significant decrease in KOR1-IR associated with peptide-containing vesicles and a significant increase in KOR1-IR associated with the plasma membrane. This stimulus-dependent translocation of receptors to the presynaptic plasma membrane provides a novel mechanism for regulation of transmitter release.

Key words: translocation; $\kappa$ opioid receptor; vasopressin; regulated secretory pathway; pituitary; neurosecretory neurons; trafficking
Multiple mechanisms have been identified that regulate the availability of receptors for ligand binding. For example, changes in gene expression, phosphorylation, and internalization are established cellular mechanisms that alter receptor availability and ultimately receptor-mediated signal transduction across the plasma membrane (Bohm et al., 1997). Another mechanism that may regulate receptor availability for ligand binding is stimulusdependent insertion of receptors into the plasma membrane. Several types of integral membrane proteins, such as glucose transporters (James et al., 1994), GABA transporters (Quick et al., 1997), and calcium channels (Passafaro et al., 1996), have been shown to translocate to the plasma membrane during regulated exocytosis. In addition, an in vitro study has recently shown that dopamine D1 receptors expressed by tubular epithelial cells from the kidney can be recruited to the plasma membrane in response to D1 agonists (Brismar et al., 1998).

In neurons, most receptors appear to be constitutively installed into the plasma membrane (Zhang et al., 1998). However, light microscopic immunohistochemical studies of the cloned opioid receptors have lead us to hypothesize that certain presynaptic receptors may be transported in the regulated secretory pathway and require nerve stimulation to be inserted in the plasma membrane (Dado et al., 1993; Elde et al., 1995). Data from several ultrastructural immunocytochemical studies extend these results by demonstrating $\delta$ opioid receptor immunoreactivity (IR) and $\kappa$ opioid receptor (KOR1)-IR associated with structures resembling large dense-core vesicles in dorsal root ganglia, spinal cord, and hippocampus (Cheng et al., 1995; Drake et al., 1996; Zhang et al., 1998). However, translocation of receptors to the presynaptic

\footnotetext{
Received Dec. 21, 1998; revised Jan. 19, 1999; accepted Jan. 21, 1999.

This research was supported by grants from the National Institute on Drug Abuse. We acknowledge and thank J. Wang and G. Kalyuzhnaya for their technical assistance.

Correspondence should be addressed to Robert Elde, University of Minnesota, 123 Snyder Hall, 1475 Gortner Avenue, St. Paul, MN 55108.

Copyright (C) 1999 Society for Neuroscience $0270-6474 / 99 / 192658-07 \$ 05.00 / 0$
}

plasma membrane has not been directly examined or demonstrated in neurons.

Presynaptic $\kappa$ opioid receptors have been shown to exist in various regions of the brain (Schoffelmeer et al., 1988; Werling et al., 1988; Mulder et al., 1991; Schoffelmeer et al., 1997), including the axon terminals of hypothalamic magnocellular neurosecretory neurons (MNN) (Herkenham et al., 1986; Boersma et al., 1994). There are two principal types of MNN, vasopressin- or oxytocin-producing. $\kappa$ opioid receptor function (Van Wimersma Greidanus and Van de Heijning, 1993) and peptidergic neurosecretion (Hatton, 1990; Palkovits, 1992) have been extensively studied in MNN axon terminals in the posterior pituitary. $\kappa$ opioid receptors are found on the terminals of MNN that contain vasopressin (Herkenham et al., 1986; Kato et al., 1992; Boersma et al., 1994). Dynorphin acts on these presynaptic receptors to decrease calcium currents (Rusin et al., 1997) and peptide release (Zhao et al., 1988). Dehydration can cause vasopressin release (Bourque et al., 1994), making these neurons easily manipulated in vivo. The existence of presynaptic $\kappa$ opioid receptors, the abundance of secretory vesicles within these terminals, and the ease of manipulation of these neurons in vivo by dehydration make this is an ideal system to study the delivery of presynaptic KOR1 to the plasma membrane.

Therefore, we examined stimulus-dependent translocation of presynaptic receptors by studying KOR1 distribution in vasopressin MNN. First, we conducted cellular and subcellular immunohistochemical analysis of KOR1 and vasopressin-neurophysin (VPNP) in the cell bodies and axons of hypothalamic MNN. VPNP, a portion of the propeptide containing the neuropeptide vasopressin, is found in large secretory vesicles that are released from terminals in the neural lobe of the pituitary (Dreif uss, 1975). Association of the peptide VPNP and KOR1 with the same large secretory vesicle would suggest that access of KOR1 to the plasma membrane is stimulus-dependent. Second, because vasopressin secretion has been shown to be markedly increased by dehydra- 
tion and salt-loading (Bourque et al., 1994; Shoji et al., 1994), rats were salt-loaded by an injection of hypertonic saline. This experiment tested the hypothesis that if presynaptic KOR1 is inserted into the plasma membrane during regulated exocytosis, saltloading would result in translocation of KOR1 to the plasma membrane.

\section{MATERIALS AND METHODS}

In all experiments, animals were used and cared for in accordance with the animal care guidelines established by the University of Minnesota.

Antibodies. The KOR1 antiserum was produced in female rabbits (New Zealand White; Birch Wood, Red Wing, MN) by immunization with a conjugate of the $\mathrm{C}$ terminus of the rat KOR1 sequence (366-380, DPASMRDVGGMNKPV). The antiserum has been previously described and characterized (Arvidsson et al., 1995). VPNP antibodyproducing mouse hybridomas were purchased from American Type Culture Collection (Manassas, VA) (CRL-1799, clone PS41).

Immunohistochemistry. For light microscopy, male Sprague Dawley rats (150-200 gm; Harlan Sprague Dawley, Indianapolis, IN) were processed for immunohistochemistry as described previously (Vulchanova et al., 1996). Briefly, animals were anesthetized with an intramuscular injection of a mixture of $75 \mathrm{mg} / \mathrm{kg}$ ketamine, $5 \mathrm{mg} / \mathrm{kg}$ xylazine, and 1 $\mathrm{mg} / \mathrm{kg}$ acepromazine. The animals were then perfused transcardially first with a calcium-free Tyrode's solution, followed by a modified Zamboni's fixative ( $4 \%$ paraformaldehyde and $0.2 \%$ picric acid, $\mathrm{pH} 6.9$ ), and finally with $10 \%$ sucrose in PBS. The tissues were removed and left overnight in $10 \%$ sucrose solution at $4^{\circ} \mathrm{C}$. The tissues were then frozen, sectioned on a cryostat, and processed for immunohistochemistry. Thawmounted cryostat sections $(14 \mu \mathrm{m})$ were preincubated in blocking buffer (PBS, $0.3 \%$ Triton X-100, $1 \%$ BSA, $1 \%$ normal donkey serum, and $0.01 \%$ $\mathrm{NaN}_{3}$ ) for $1 \mathrm{hr}$ at room temperature, followed by overnight incubation with anti-KOR1 $(1: 10,000)$ antisera alone or in combination with antiVPNP (1:50) antibodies at $4^{\circ} \mathrm{C}$ (clone PS41). VPNP-IR was detected with fluorescently conjugated, mouse-specific secondary antibodies (1: 100; Jackson ImmunoResearch, West Grove, PA). KOR1-IR was amplified using the biotinylated tyramine amplification technique (Adams, 1992; Berghorn et al., 1994). Briefly, after incubation in anti-KOR1 antisera, sections were incubated in biotinylated goat anti-rabbit IgG for $1 \mathrm{hr}$ at room temperature. Sections were incubated in a horseradish peroxidase-coupled avidin-biotin complex for $30 \mathrm{~min}$ (Vector Elite; Vector Laboratories, Burlingame, CA). Next, the sections were incubated in a biotinylated tyramine and $\mathrm{H}_{2} \mathrm{O}_{2}(0.03 \%)$ solution for $20 \mathrm{~min}$. KOR1-IR was visualized using fluorescently conjugated streptavidin (1:200; Vector Laboratories). Images were acquired by confocal microscopy (Bio-Rad 1000; Bio-Rad, Hercules, CA) and printed on a Fuji (Tokyo, Japan) Pictrography 3000.

For electron microscopy, male Sprague Dawley rats (150-200 gm) were anesthetized as above and perfusion-fixed (4\% paraformaldehyde, $0.1 \%$ picric acid, and $0.05 \%$ glutaraldehyde in phosphate buffer, $\mathrm{pH} 7.4$ ), and the tissues were processed as described below. The neural lobe was removed and post-fixed at $4^{\circ} \mathrm{C}$ for $3 \mathrm{hr}$ in perfusion solution, followed by $1 \mathrm{hr}$ fixation in $1 \%$ osmium tetroxide and $1.5 \%$ potassium ferricyanide at room temperature. After ethanol-dehydration, tissues were cleared in propylene oxide and embedded in Epon-Araldite resin according to standard embedding protocols. Ultrathin sections were cut with a diamond knife and collected on uncoated 300 mesh nickel grids. Grids were preincubated in blocking buffer (1\% BSA and 10\% NGS in PBS, pH 7.4) for $10 \mathrm{~min}$ and labeled with anti-KOR1 (1:1000) antisera alone or in combination with anti-VPNP $(1: 50)$ for $3 \mathrm{hr}$ at room temperature. Immunoreactivity was detected with gold-conjugated species-specific secondary antibodies (Ted Pella, Redding, CA or Nanoprobes, Stony Brook, NY). In double-labeling experiments, different size colloidal gold particles $(5$ and $15 \mathrm{~nm})$ were used to differentiate between anti-VPNP and anti-KOR1. Images were acquired using a JEOL (Tokyo, Japan) CX electron microscope, digitized, processed, and printed on a Fuji Pictrography 3000 .

Quantification of KOR1 subcellular distribution and translocation. Normal Sprague Dawley rats (150-200 gm) were processed for immunogold electron microscopy as described above. Fourteen meshes, randomly selected from five grids ( 300 mesh grids, Ted Pella) that contained tissue from the neural lobe of two rats, were used for quantification. If two or more gold particles were associated with a given subcellular compartment, it was counted as positive for KOR1-IR. Subcellular compartments were defined as plasma membrane, large secretory vesicles, cytoplasm, and small synaptic-like microvesicles. Data were pooled (each grid was considered a group; $n=5$ ), the mean \pm SE was determined, and results were expressed as percentage of total KOR1-IR.

To assess stimulus-dependent KOR1 translocation to the plasma membrane, male Sprague Dawley rats $(150-200 \mathrm{gm})$ received an intraperitoneal injection of $2 \mathrm{ml} / 100 \mathrm{gm}$ body weight $0.9 \mathrm{M} \mathrm{NaCl}(n=3)$ or sham injection $(n=3)$. In sham-injected control animals, the needle was inserted without saline delivery. Animals were anesthetized and perfusion-fixed (4\% paraformaldehyde, $0.1 \%$ picric acid, and $0.05 \%$ glutaraldehyde in phosphate buffer) 15 and 60 min after injection, and tissue was processed for electron microscopy. Gold particles representing KOR1-IR were counted as above, and subcellular compartments were defined as plasma membrane, large secretory vesicles, cytoplasm, small synaptic-like microvesicles, and other vesicles. Subcellular distribution of KOR1-IR was determined from 464 nerve terminals. The subcellular distribution of KOR1-IR was determined for each animal, and the mean for each group ( $n=3$ animals per group; groups defined as control and salt-loaded) was calculated. Statistical significance was determined using an unpaired Student's $t$ test $(p<0.05)$.

\section{RESULTS}

\section{Cellular and subcellular distribution of KOR1- and VPNP-IR}

The cellular and subcellular localization of KOR1 and VPNP was determined in cell bodies, axons, and axon terminals of MNN in rats. KOR1- and VPNP-IR were colocalized in a subset of cells within the paraventricular and supraoptic nuclei in the hypothalamus (Fig. 1). Not all KOR1-IR neurons were VPNP-positive. KOR1-IR neurons that were not VPNP-positive within these nuclei may be oxytocin-positive. However, the histological relationship between KOR1 and oxytocin needs to be directly examined. Double-labeled sections also showed colocalization of KOR1- and VPNP-IR in a subset of axons passing through the internal layer of the median eminence (Fig. $2 A, B$ ) and within axon terminals of the neural lobe (Fig. $2 C, D$ ). Higher magnification of the internal layer of the median eminence revealed puncta positive for both KOR1 and VPNP staining (Fig. 2B, arrows). Individual axon terminals of the neural lobe also contained KOR1- and VPNP-IR (Fig. 2D, arrows).

The subcellular distribution of KOR1-IR was examined using electron microscopy to understand the relationship of KOR1-IR to organelles and membranes of axon terminals in the neural lobe. Immunogold labeling of ultrathin sections revealed that KOR1-IR was only occasionally associated with the plasma membrane of nerve terminals (Fig. $3 E$ ). KOR1-IR was most often associated with the membrane of large secretory vesicles that are typical of peptidergic terminals in the neural lobe (Boersma et al., 1993) (Fig. 3A,C,D). In single-labeled serial sections, individual terminals were identified that contained both KOR1- and VPNPIR. Moreover, individual vesicles that were positive for KOR1-IR contained VPNP-IR within their lumen (Fig. 3A,B, arrows). Colocalization of KOR1- and VPNP-IR in the same vesicle was confirmed in double-labeled sections of the neural lobe (Fig. 3C).

\section{Quantification of subcellular distribution and receptor translocation}

A quantitative analysis of single-labeled sections was performed to determine the relative subcellular distribution of KOR1-IR within terminals in the neural lobe. In normal untreated animals, $61.5 \%$ of KOR1-IR was associated with the membrane of large secretory vesicles, whereas only $10.7 \%$ of KOR1-IR was associated with the plasma membrane (Fig. 4). In addition, KOR1-IR was seen associated with the cytoplasm and other vesicles, including small synaptic-like microvesicles, multivesicular bodies, and other pleiomorphic vesicles. 

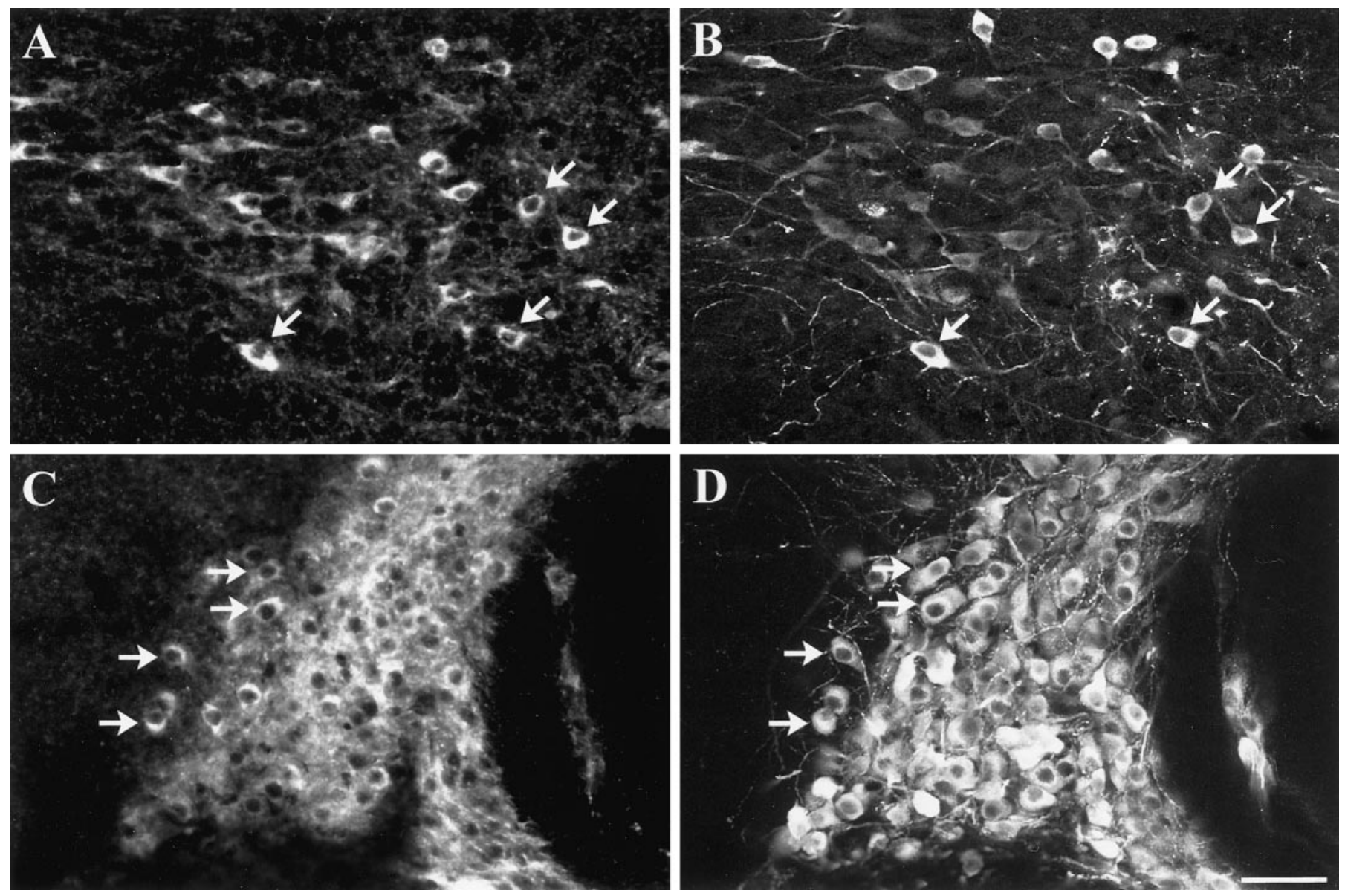

Figure 1. KOR1- and VPNP-IR colocalize in the cell bodies of hypothalamic MNN. Confocal micrographs of KOR1 $(A, C)$ and VPNP $(B, D)$ double-labeled single sections. $A, B$, Single section of rat paraventricular nucleus double-labeled for KOR1-IR $(A)$ and VPNP-IR $(B)$. Examples of KOR1 and VPNP colocalization within cell bodies are indicated by arrows. $C, D$, Single section of rat supraoptic nucleus double-labeled for KOR1-IR $(C)$ and VPNP-IR $(D)$. Examples of KOR1 and VPNP colocalization within cell bodies are indicated by arrows. Scale bar: $A-D, 100 \mu \mathrm{m}$.

To assess whether KOR1 is inserted into the plasma membrane during regulated exocytosis, rats were acutely salt-loaded. Acute salt-loading has been shown to result in an increase in vasopressin secretion (Shoji et al., 1994). Fifteen minutes after salt-loading by intraperitoneal saline administration, there was a significant reduction of KOR1-IR associated with large secretory vesicles and a significant increase in KOR1-IR associated with the plasma membrane compared with sham-injected control animals (Fig. 5). The amount of KOR1-IR associated with the plasma membrane in salt-loaded animals was $178 \%$ of sham-injected control animals. There was no change in KOR1-IR in other subcellular compartments, including cytoplasm, small synaptic-like microvesicles, and other nonclassified vesicles (data not shown). In contrast, $60 \mathrm{~min}$ after saline injection, the subcellular distribution of KOR1 was not significantly different from control animals (Fig. 5 ) in any subcellular compartment, including large secretory vesicles and the plasma membrane.

\section{DISCUSSION}

\section{Cellular and subcellular distribution of KOR1-IR}

We have shown that the cloned $\kappa$ opioid receptor colocalizes with VPNP in the cell bodies, axons, and axon terminals of MNN. In addition, we have shown that KOR1- and VPNP-IR colocalize in large secretory vesicles within the posterior pituitary. Finally, we have demonstrated that the majority of KOR-IR is associated with large secretory vesicles.

The cellular immunohistochemical distribution of KOR1 is in agreement with other immunohistochemical and physiological data. It has been shown previously that the cloned $\kappa$ opioid receptor is found in MNN and in the posterior pituitary (Arvidsson et al., 1995; Mansour et al., 1996). Physiological evidence that $\kappa$ opioid receptor agonists cause an inhibition of vasopressin release also suggests that $\kappa$ opioid receptors are found in vasopressin-containing cell bodies (Rossi and Brooks, 1996) and nerve terminals (Zhao et al., 1988; Rusin, 1997). This, however, is the first histological demonstration of the colocalization of KOR1 and VPNP within the same presynaptic vasopressincontaining nerve terminals.

The subcellular distribution of KOR1 within the posterior lobe of the pituitary is also consistent with ultrastructural analysis of opioid receptors. First, KOR1-IR has been shown to be associated with large dense-core vesicles within the hippocampus (Drake et al., 1996). Second, $\delta$ opioid receptor immunoreactivity has been shown to be associated with a variety of vesicles within the spinal cord, including large-dense core vesicles (Cheng et al., 1995; Z hang et al., 1998). Finally, Zhang et al. (1998) have shown $\delta$ opioid receptor immunoreactivity to be associated with newly synthesized large dense-core vesicles in the vicinity of the Golgi 

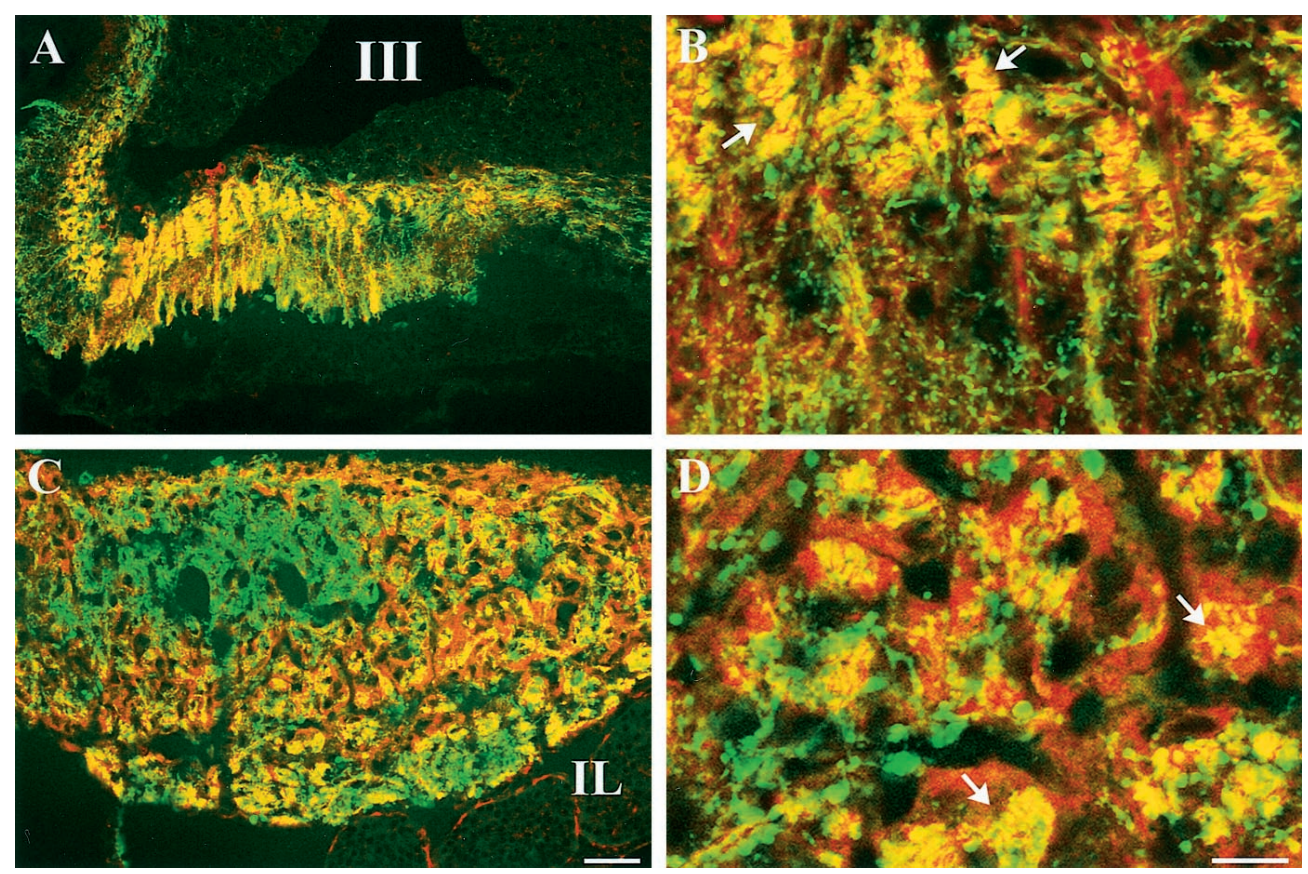

Figure 2. A large portion of KOR1- and VPNP-IR colocalize in the same structures in the axons of the median eminence and nerve terminals within the neural lobe of the pituitary. Confocal micrographs of KOR1-IR (red) and VPNP-IR (green) in double-labeled single sections of rat median eminence $(A$, $B)$ and posterior pituitary $(C, D)$. Instances of colocalization are indicated by yellow (and arrows), created by the digital merging of red (KOR-IR) and green (VPNP-IR). $A$, Low-magnification image of median eminence showing colocalization of KOR1- and VPNP-IR within the internal layer of the median eminence and scattered fibers in the external layer. $B$, High-magnification image showing colocalization of KOR1- and VPNP-IR in discrete puncta in a subset of fibers within the internal layer of the median eminence. $C$, Low-magnification image of nerve terminals within the neural lobe that are positive for both KOR1and VPNP-IR. D, High-magnification image showing that KOR1- and VPNP-IR are colocalized within a subpopulation of the nerve terminals. Scale bars: (in $C$ ) $A, C, 50 \mu \mathrm{m}$; (in $D$ ) $B, D, 30$ $\mu \mathrm{m}$. III, Third ventricle; $I L$, intermediate lobe of the pituitary. complex within dorsal root ganglia. In the present study, we show that $\sim 60 \%$ of KOR1-IR in the posterior pituitary is associated with large secretory vesicles, suggesting that these receptors are transported from the cell body to the axon terminals in peptidecontaining vesicles. Association of the $\kappa$ opioid receptor with large secretory vesicles also suggests that it is transported in the regulated pathway as opposed to the constitutive pathway.

\section{Stimulus-dependent translocation}

We have demonstrated that the insertion of presynaptic KOR1 into the plasma membrane of nerve terminals within the neural lobe of the pituitary occurs during regulated exocytosis. This stimulus-dependent translocation is analogous to the secretion of a neuropeptide (Fig. 6). Neuropeptide secretion requires sustained depolarization, resulting in an influx of calcium through voltage-gated calcium channels. The rise in intracellular calcium concentration initiates fusion of large secretory vesicles with the plasma membrane, resulting in release of neuropeptides into the extracellular space (Morgan, 1995; Lledo, 1997). In this model, presynaptic receptors associated with the membrane of neuropeptide-containing vesicles can be translocated to the plasma membrane and gain access to the extracellular space only after neuropeptide release.

It is unclear whether stimulus-dependent translocation of receptors is a common mechanism for insertion of presynaptic receptors into the plasma membrane. However, several results suggest that this mechanism does occur. First, recent ultrastructural immunocytochemical studies outlined above suggest that, at least for presynaptic opioid receptors, this may be a common mechanism. The presence of these receptors on large dense-core vesicles strongly suggests that depolarization sufficient to cause neuropeptide secretion can cause translocation of these receptors to the plasma membrane.

Second, dopamine D1 receptors have been shown to be recruited from the cytoplasm, presumably from an intracellular vesicular compartment, to the plasma membrane within the renal proximal tubule and the cell line LLCPK1, which mimics renal proximal tubular cells (Brismar et al., 1998). In this study, D1 receptor agonists caused an increase of D1 receptor on the plasma membrane, presumably by initiating a calcium-dependent intracellular signaling event that caused translocation of the receptors to the plasma membrane. This study showed that a G-protein-coupled receptor can translocate to the plasma membrane and supports our result that this mechanism can occur in presynaptic nerve terminals. In addition, other integral membrane proteins, such as various transporters (James et al., 1994; Quick et al., 1997), have also been shown to be translocated from an intracellular compartment to the plasma membrane in response to appropriate stimuli.

Third, observations made by Laduron (1984) lend support to the idea that some presynaptic receptors are transported to the plasma membrane via the regulated pathway. This study examined the rates of anterograde and retrograde transport of presynaptic receptors. It was concluded that presynaptic muscarinic receptors in noradrenergic neurons are associated with small synaptic vesicles, possibly those containing noradrenaline and dopamine- $\beta$-hydroxylase. However, because the vesicles were analyzed indirectly from a density gradient, it is possible that the vesicles containing muscarinic receptors are a distinct population and are merely segregated with those containing noradrenaline and dopamine- $\beta$-hydroxylase.

Finally, most pertinent to the present study is the recent demonstration in various cell lines that $\mathrm{N}$-type voltage-gated calcium channels reside in the membrane of large dense-core vesicles and that their translocation to the plasma membrane is stimulusdependent (Passafaro et al., 1996, 1998). Using subcellular fractionation and density gradient isolation, these studies showed that $\mathrm{N}$-type calcium channels were localized to the peptidecontaining, large dense-core vesicle fraction. In addition, they 
Figure 3. KOR1-IR is associated with the membrane of large secretory vesicles containing VPNP-IR. Transmission electron microscopy micrographs of postembedding-immunogold staining for KOR1 (15 nm gold) and VPNP (5 $\mathrm{nm}$ gold) within the neural lobe. Serial sections single-labeled with anti-KOR1 $(A)$ and anti-VPNP $(B)$. The same vesicle (small arrows) is labeled with KOR1- and VPNP-IR in both sections $(A, B)$. C, Single section double-labeled with anti-KOR1 (15 nm) and antiVPNP (5 nm) also showing KOR1- and VPNP-IR colocalized in the same large secretory vesicle (large arrow). Singlelabeled sections showing KOR1-IR on the membrane of a large secretory vesicle $(D)$ and the plasma membrane $(E)$. Scale bars: (in $B) A, B, 250 \mathrm{~nm} ; C, 100$ nm; (in $E) D, E, 100 \mathrm{~nm}$.
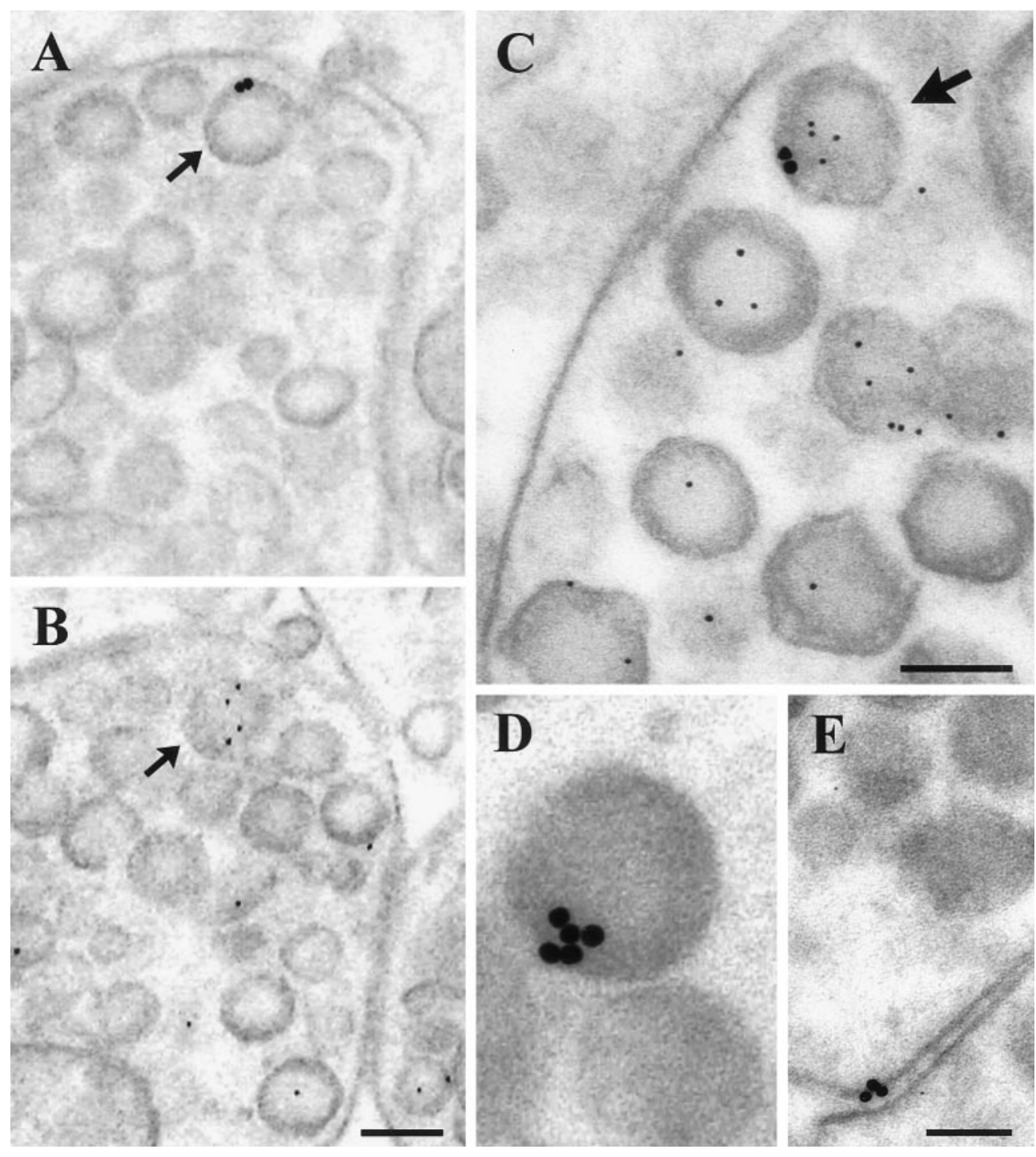

showed that stimulation, which induced release of peptides segregated to the regulated secretory pathway, also caused insertion of calcium channels into the plasma membrane. Moreover, they demonstrated that this was a calcium-dependent event.

In addition to stimulus-dependent insertion in the plasma membrane, we have also demonstrated that this increase in KOR1-IR on the plasma membrane is transient. The distribution of KOR1-IR 60 min after acute salt-loading was not different from control. KOR1 was presumably removed from the plasma membrane within 60 min of an initial stimulus-dependent insertion. Although ligand-mediated endocytosis has been demonstrated for both the $\mu$ and $\delta$ opioid receptors (Sternini et al., 1996; Trapaidze et al., 1996; Gaudriault et al., 1997), as well as other G-protein-coupled receptors, the mechanism responsible for endocytosis of presynaptic KOR1 has not been characterized (Chu et al., 1997). Both the stimulus-dependent insertion and subsequent removal of presynaptic KOR1 from the plasma membrane suggest that its availability for ligand binding is under precise temporal regulation.

\section{Functional Implications}

$\kappa$ opioid agonists have been shown to decrease calcium conductance in the neural lobe and thereby inhibit transmitter release
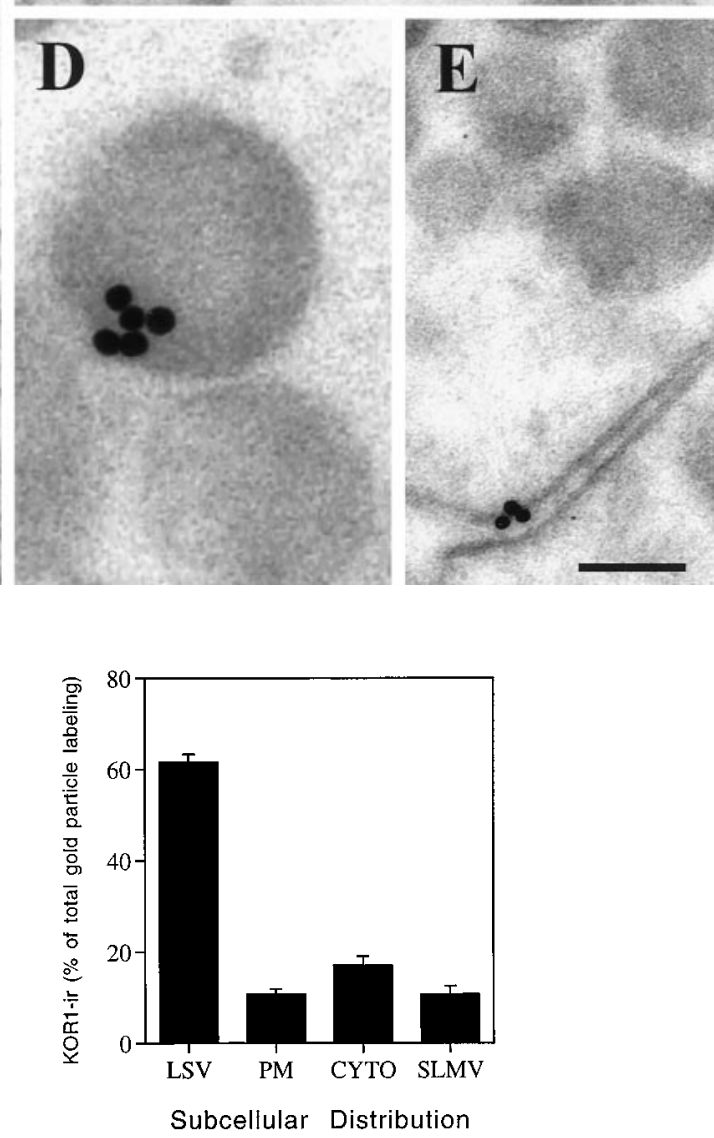

Figure 4. Subcellular distribution of KOR1 in the nerve terminals of rat posterior pituitary. The graph shows the summary of the quantification of immunogold particles representing KOR1-IR, expressed as percentage of total KOR1-IR. Subcellular compartments were defined as large secretory vesicles $(L S V)$, plasma membrane $(P M)$, cytoplasm $(C Y T O)$, and synaptic-like microvesicles $(S L M V)$. Large secretory vesicles, $62.5 \pm$ $1.8 \%$; plasma membrane, $10.8 \pm 1.2 \%$; cytoplasm, $17 \pm 2.1 \%$; synapticlike microvesicles, $10.7 \pm 1.8 \%$. Error bars indicate \pm SEM. 


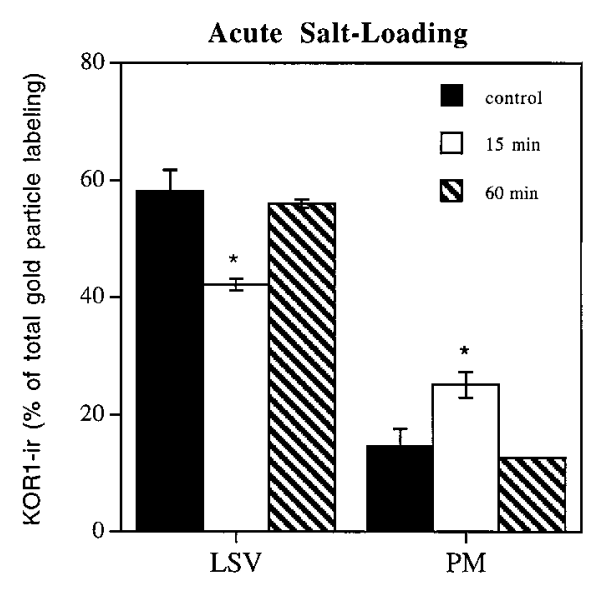

Subcellular Distribution

Figure 5. KOR1-IR translocates to the plasma membrane from large secretory vesicles in a stimulus-dependent manner. Experimental animals $(n=3)$ were treated with an intraperitoneal injection of hypertonic saline 15 or 60 min before perfusion fixation. In control animals $(n=3)$, a needle was inserted and withdrawn without the delivery of saline. The graph shows the summary of the quantification of immunogold particles representing KOR1-IR, expressed as percentage of total KOR1-IR. The values shown represent the mean \pm SEM. Gold particles were counted in 464 nerve terminals. Control: large secretory vesicles, $58.2 \pm 3.6 \%$; plasma membrane, $14.6 \pm 3.0 \%$; 15 min stimulation: large secretory vesicles, $42.1 \pm 1.0 \%$; plasma membrane, $25.2 \pm 2.2 \%$; 60 min stimulation: large secretory vesicles, $56.0 \pm 0.7 \%$; plasma membrane, $12.8 \pm$ $0.2 \%$. ${ }^{*} p<0.05$. Error bars indicate \pm SEM.

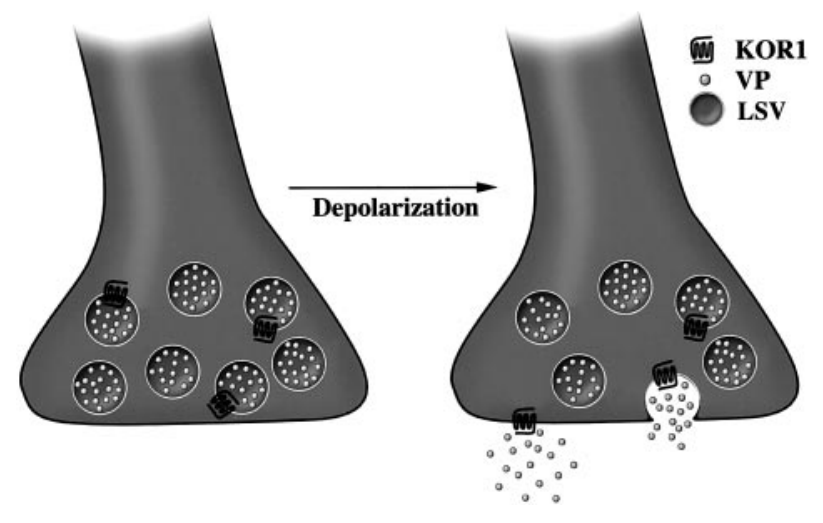

Figure 6. Schematic illustration showing translocation of presynaptic KOR1 from its transport vesicle to the plasma membrane. In the nerve terminals of the neural lobe, KOR1 appears to be transported in vesicles containing vasopressin $(V P)$. Conditions that cause depolarization and release of neurohormone appear to cause KOR1 to be inserted into the plasma membrane, giving the receptor access to its ligand to transduce a signal across the plasma membrane.

(Rusin et al., 1997). Vasopressin-containing neurosecretory neurons are known to produce and corelease other neuropeptides, including dynorphin (Watson et al., 1982; Meister et al., 1990), the endogenous opioid that binds with the highest affinity to KOR1. Our results suggest that dynorphin would have access to a greater number of KOR1 receptors after an initial depolarization. Stimulus-dependent translocation of KOR1 to the plasma membrane may result in an increased probability of dynorphin binding to KOR1. Increased dynorphin binding would result in a reduction of subsequent neuropeptide release.

Vasopressin and dynorphin have been shown to coexist within the same secretory vesicle (Whitnall et al., 1983). Our study does not address whether the vesicles that contain both vasopressin and KOR1 also contain dynorphin. Even if dynorphin were present in large secretory vesicles containing KOR1, receptor-ligand interaction would probably not occur within the vesicle. The binding site of KOR1 would be facing dynorphin in the lumen of the vesicle, but both the low $\mathrm{pH}$ and the condensation of peptides within the vesicle would not allow receptor-ligand interaction. We believe that the receptor is being transported and stored in the vesicle and that, although it is associated with the vesicle membrane, it does not modulate cellular activity. Moreover, it is unclear whether the receptor, once inserted into the plasma membrane, is immediately available for ligand binding and signal transduction or whether KOR1 first requires modification, such as conformational changes or coupling to G-proteins, to interact with ligands.

Receptor function is controlled by a variety of mechanisms. Stimulus-dependent translocation of presynaptic receptors from their site of storage to the plasma membrane may serve as another regulatory mechanism of presynaptic function. The present results indicate that regulated exocytosis not only delivers secreted peptides and proteins to the extracellular space but can also bring to the plasma membrane the receptors necessary to modulate further neuropeptide release.

\section{REFERENCES}

Adams JC (1992) Biotin amplification of biotin and horseradish peroxidase signals in histochemical stains. J Histochem Cytochem 40:1457-1463.

Arvidsson U, Riedl M, Chakrabarti S, Vulchanova L, Lee J-H, Nakano AH, Lin X, Loh HH, Law P-Y, Wessendorf MW, Elde R (1995) The $\kappa$-opioid receptor (KOR1) is primarily postsynaptic: combined immunohistochemical localization of the receptor and endogenous opioids. Proc Natl Acad Sci USA 92:5062-5066.

Berghorn KA, Bonnett JH, Hoffman GE (1994) cFos immunoreactivity is enhanced with biotin amplification. J Histochem Cytochem 42:1635-1642.

Boersma CJC, Sonnemans MA, Van Leeuwen FW (1993) Immunoelectron microscopic demonstration of oxytocin and vasopressin in pituicytes and in nerve terminals forming synaptoid contacts with pituicytes in the rat neural lobe. Brain Res 611:117-129.

Boersma CJC, Pool CW, Van Heerikhuize J, Van Leeuwen FW (1994) Characterization of opioid binding sites in the neural and intermediate lobe of the rat pituitary gland by quantitative receptor autoradiography. J Neuroendocrinol 6:47-56.

Bohm SK, Grady EF, Bunnett NW (1997) Regulatory mechanisms that modulate signalling by G-protein-coupled receptors. Biochem J 322:1-18.

Bourque CW, Oliet SH, Richard D (1994) Osmoreceptors, osmoreception, and osmoregulation. Front Neuroendocrinol 15:231-274.

Brismar H, Asghar M, Carey RM, Greengard P, Aperia A (1998) Dopamine-induced recruitment of dopamine D1 receptors to the plasma membrane. Proc Natl Acad Sci USA 95:5573-5578.

Cheng PY, Svingos AL, Wang H, Clarke CL, Jenab S, Beczkowska IW, Inturrisi CE, Pickel VM (1995) Ultrastructural immunolabeling shows prominent presynaptic vesicular localization of $\delta$-opioid receptor within both enkephalin- and nonenkephalin-containing axon terminals in the superficial layers of the rat cervical spinal cord. J Neurosci 15:5976-5988.

Chu P, Murray S, Lissin D, von Zastrow M (1997) $\delta$ and $\kappa$ opioid receptors are differentially regulated by dynamin-dependent endocytosis when activated by the same alkaloid agonist. J Biol Chem 272:27124-27130.

Dado RJ, Law PY, Loh HH, Elde R (1993) Immunofluorescent identification of a $\delta$-opioid receptor on primary afferent nerve terminals. NeuroReport 5:341-344.

Drake CT, Patterson TA, Simmons ML, Chavkin C, Milner TA (1996) $\kappa$ opioid receptor-like immunoreactivity in guinea pig brain: ultrastructural localization in presynaptic terminals in hippocampal formation. J Comp Neurol 370:377-395. 
Dreifuss JJ (1975) A review on neurosecretory granules: their contents and mechanisms of release. Ann NY Acad Sci 248:184-201.

Elde R, Arvidsson U, Riedl M, Vulchanova L, Lee JH, Dado R, Nakano A, Chakrabarti S, Zhang X, Loh HH, Law PY, Hökfelt T, Wessendorf M (1995) Distribution of neuropeptide receptors. New views of peptidergic neurotransmission made possible by antibodies to opioid receptors. Ann NY Acad Sci 757:390-404.

Gaudriault G, Nouel D, Dal Farra C, Beaudet A, Vincent JP (1997) Receptor-induced internalization of selective peptidic $\mu$ and $\delta$ opioid ligands. J Biol Chem 272:2880-2888.

Hatton GI (1990) Emerging concepts of structure-function dynamics in adult brain: the hypothalamo-neurohypophysial system. Prog Neurobiol 34:437-504.

Herkenham M, Rice KC, Jacobson AE, Rothman RB (1986) Opiate receptors in rat pituitary are confined to the neural lobe and are exclusively $\kappa$. Brain Res 382:365-371.

James DE, Piper RC, Slot JW (1994) Insulin stimulation of GLUT-4 translocation: a model for regulated recycling. Trends Cell Biol 4:120-126.

Kato M, Chapman C, Bicknell RJ (1992) Activation of $\kappa$-opioid receptors inhibits depolarisation-evoked exocytosis but not the rise in intracellular $\mathrm{Ca}^{2+}$ in secretory nerve terminals of the neurohypophysis. Brain Res 574:138-146.

Laduron PM (1984) Axonal transport of muscarinic receptors in vesicles containing noradrenaline and dopamine- $\beta$-hydroxylase. FEBS Letters 165:128-132.

Lledo PM (1997) Exocytosis in excitable cells: a conserved molecular machinery from yeast to neuron. Eur J Endocrinol 137:1-9.

Mansour A, Burke S, Pavlic RJ, Akil H, Watson SJ (1996) Immunohistochemical localization of the cloned $\kappa$ receptor in the rat CNS and pituitary. Neuroscience 71:671-690.

Meister B, Villar MJ, Ceccatelli S, Hökfelt T (1990) Localization of chemical messengers in magnocellular neurons of the hypothalamic supraoptic and paraventricular nuclei: an immunohistochemical study using experimental manipulations. Neuroscience 37:603-633.

Morgan A (1995) Exocytosis. Essays Biochem 30:77-95.

Mulder AH, Burger DM, Wardeh G, Hogenboom F, Frankhuyzen AL (1991) Pharmacological profile of various $\kappa$-agonists at $\kappa-, \mu$ - and $\delta$-opioid receptors mediating presynaptic inhibition of neurotransmitter release in the rat brain. Br J Pharmacol 102:518-522.

Palkovits M (1992) Peptidergic neurotransmitters in the endocrine hypothalamus. Ciba Found Symp 168:3-15.

Passafaro M, Rosa P, Sala C, Clementi F, Sher E (1996) N-type Ca ${ }^{2+}$ channels are present in secretory granules and are transiently translocated to the plasma membrane during regulated exocytosis. J Biol Chem 271:30096-30104.

Passafaro M, Taverna E, Morlacchi E, Rosa P, Clementi F, Sher E (1998) Transient translocation of N-type calcium channels from secretory granules to the cell surface. Ann NY Acad Sci 841:119-121.

Quick MW, Corey JL, Davidson N, Lester HA (1997) Second messengers, trafficking-related proteins, and amino acid residues that contrib- ute to the functional regulation of the rat brain GABA transporter GAT1. J Neurosci 17:2967-2979.

Rossi NF, Brooks DP (1996) kappa-Opioid agonist inhibition of osmotically induced AVP release: preferential action at hypothalamic sites. Am J Physiol 33:E367-E372.

Rusin KI, Giovannucci DR, Stuenkel EL, Moises HC (1997) $\kappa$-Opioid receptor activation modulates $\mathrm{Ca}^{2+}$ currents and secretion in isolated neuroendocrine nerve terminals. J Neurosci 17:6565-6574.

Schoffelmeer AN, Rice KC, Jacobson AE, Van Gelderen JG, Hogenboom F, Heijna MH, Mulder AH (1988) $\mu$-, $\delta$ - and $\kappa$-opioid receptormediated inhibition of neurotransmitter release and adenylate cyclase activity in rat brain slices: studies with fentanyl isothiocyanate. Eur J Pharmacol 154:169-178.

Schoffelmeer AN, Hogenboom F, Mulder AH (1997) $\kappa 1$ - and $\kappa 2$-opioid receptors mediating presynaptic inhibition of dopamine and acetylcholine release in rat neostriatum. Br J Pharmacol 122:520-524.

Shoji M, Kimura T, Kawarabayasi Y, Ota K, Inoue M, Yamamoto T, Sato K, Ohta M, Funyu T, Sonoyama T, Keishi A (1994) Effects of acute salt loading on vasopressin mRNA level in the rat brain. Am J Physiol 266:R1591-R1595.

Sternini C, Spann M, Anton B, Keith Jr DE, Bunnett NW, von Zastrow M, Evans C, Brecha NC (1996) Agonist-selective endocytosis of $\mu$ opioid receptor by neurons in vivo. Proc Natl Acad Sci USA 93:9241-9246.

Trapaidze N, Keith DE, Cvejic S, Evans CJ, Devi LA (1996) Sequestration of the $\delta$ opioid receptor. Role of the $\mathrm{C}$ terminus in agonistmediated internalization. J Biol Chem 271:29279-29285.

Van Wimersma Greidanus TB, Van de Heijning BJM (1993) Opioid control of vasopressin and oxytocin release [review]. Regul Pept 45:183-186.

Vulchanova L, Arvidsson U, Riedl M, Wang J, Buell G, Surprenant A, North RA, Elde R (1996) Differential distribution of two ATP-gated channels (P2X receptors) determined by immunocytochemistry. Proc Natl Acad Sci USA 93:8063-8067.

Watson SJ, Akil H, Fischli W, Goldstein A, Zimmerman E, Nilaver G, Van Wimersma Greidanus TB (1982) Dynorphin and vasopressin: common localization in magnocellular neurons. Science 216:85-87.

Werling LL, Frattali A, Portoghese PS, Takemori AE, Cox BM (1988) $\kappa$ receptor regulation of dopamine release from striatum and cortex of rats and guinea pigs. J Pharmacol Exp Ther 246:282-286.

Whitnall MH, Gainer H, Cox BM, Molineaux CJ (1983) Dynorphin-A(1-8) is contained within vasopressin neurosecretory vesicles in rat pituitary. Science 222:1137-1139.

Zhang X, Bao L, Arvidsson U, Elde R, Hökfelt T (1998) Localization and regulation of the $\delta$-opioid receptor in dorsal root ganglia and spinal cord of the rat and monkey: evidence for association with the membrane of large dense-core vesicles. Neuroscience 82:1225-1242.

Zhao BG, Chapman C, Bicknell RJ (1988) Functional $\kappa$-opioid receptors on oxytocin and vasopressin nerve terminals isolated from the rat neurohypophysis. Brain Res 462:62-66. 